\title{
EDITORIALS
}

\section{Improving Care Transitions: Hospitalists Partnering With Primary Care}

\author{
Richard B. Balaban, MD ${ }^{1,2}$ \\ Mark V. Williams, MD, \\ FACP, FHM ${ }^{3}$ \\ ${ }^{1}$ Department of Medicine, Cambridge Health Alliance, Cambridge, Massachusetts. \\ ${ }^{2}$ Harvard Medical School, Boston, Massachusetts. \\ ${ }^{3}$ Division of Hospital Medicine, Northwestern University Feinberg School of Medicine, Chicago, Illinois.
}

Disclosure: Nothing to report.

Journal of Hospital Medicine 2010;5:375-377. ( 2010 Society of Hospital Medicine.

Hospital readmissions are common, costly in both economic and human terms, and often preventable. This "perfect storm" of attributes has placed hospital readmissions at the center of discourse among payers, providers, and policy makers, which is leading to innovations in care delivery. Evolving efforts to enhance discharge communication, to improve care coordination and accountability, and to meaningfully involve primary care, show promise of reducing readmissions. ${ }^{1-4}$ These pockets of success demonstrate that improving care transitions can increase quality of care while decreasing costs.

Within the hospital, it is now clear that the discharge process typically requires the same intensity of effort as admission. The hospitalist guides an interdisciplinary team, including nurses, pharmacists, case managers, and social workers, through a checklist of discharge tasks. Some tasks require substantial hospitalist involvement and expertise, such as medication reconciliation-a detail-oriented, time-consuming process. Other tasks can be accomplished by team members, overseen by the hospitalist, such as scheduling timely follow-up appointments, coordinating outpatient services, and assembling educational materials. Taken as a whole, significant time and effort must be devoted by the inpatient team to address the complex landscape of a patient's medical and psychosocial needs.

That of course, is only half of the equation, as patient care must be transferred to an equally invested outpatient team led by a primary care provider (PCP). Several influential medical societies have endorsed the medical home (a multidisciplinary care team led by a PCP) as the primary agent to coordinate patient care across settings. ${ }^{5}$ Indeed, promptly reconnecting with their PCP and primary care team after discharge can have profound meaning for patients, who may otherwise be unsupported with their postdischarge clinical needs. In this issue of the Journal of Hospital Medicine, 4 important articles provide evidence in support of an outpatient partner to actively assume patient care responsibility after hospital discharge.

van Walraven et al. ${ }^{6}$ conducted an elegant study to evaluate the impact of postdischarge PCP visits on readmissions.
Following more than 5000 patients for nearly 6 months, they demonstrated that increased PCP follow-up was significantly and independently associated with a decreased risk of hospital readmission. This confirms the positive impact that a primary care connection can have on postdischarge care. This study also highlights some challenges: $18 \%$ of the original cohort were excluded from the final analyses because they had only 1 or no PCP visit in the 6 months following discharge, indicating inadequate postdischarge follow-up for a substantial sub-group. Misky et al. ${ }^{7}$ similarly established that patients with "timely" PCP followup (within one month of discharge) were 10 times less likely to be readmitted for the same condition as their index admission. These are also encouraging findings for those patients with PCP follow-up. Yet among patients in their study, PCP follow-up was even less common, with only $49 \%$ of patients having appointments within one month. Future studies should consider how more intensive outreach strategies might engage difficult-to-reach patients and communities.

PCP follow-up may be beneficial because discharged patients often have ongoing issues that need to be addressed. Arora et al. ${ }^{8}$ surveyed inner city patients and their PCPs 2 weeks after hospital discharge to assess whether patients experienced any "problems" in the postdischarge period, and whether PCPs were aware of their patients' hospitalization. Nearly half of all patients recounted 1 or more postdischarge problems. The likelihood of reporting such a problem was twice as common among those patients whose PCP was unaware of their hospitalization. Again, this is strong validation of the importance of PCP involvement in posthospital care, but equally concerning is their finding that fully 3 in 10 PCPs were unaware of their patient's hospitalization.

Finally, Mitchell et al. ${ }^{9}$ further refine our understanding of risk factors for readmission. In an ethnically diverse inner city population, they screened 738 inpatients for depression. Among the 238 (32\%) patients who screened positive, there was a marked $73 \%$ increase in hospital utilization (emergency department [ED] visits and readmissions) within 30 days of discharge. ${ }^{9}$ This confirms previous research that 
depression is a risk factor for rehospitalization. ${ }^{10}$ Depression, however, is amenable to treatment and receiving care through one's primary care practice can potentially mitigate how depression negatively affects patients' medication adherence, self-care behavior, and ultimately readmission rates.

Collectively, these 4 articles give us reason to experience both despair and hope. It is discouraging that large numbers of patients do not have timely encounters with their PCP after discharge, confirming previous findings, ${ }^{11}$ and that too often PCPs are unaware of their patients' hospitalizations. In any other industry this sort of inefficiency and poor customer service would put a company out of business; that it persists in medicine is embarrassing. Because our medical system is not sufficiently incentivized by quality outcomes, such poor practices continue to be tolerated, and our patients suffer the consequences.

But we are also shown a way forward, with accumulating evidence complimenting existing studies that a primary care connection can improve the quality of postdischarge care and decrease readmissions. ${ }^{12-14}$ Recognizing this central role of primary care, however, forces us to acknowledge the diminishing availability of primary care nationwide; in many inner city and rural locations, accessible primary care is largely nonexistent. This shortage must be corrected to attain needed access and to advance health care reform.

Postdischarge PCP involvement is particularly essential with shorter hospital stays, as patients will predictably have complex postdischarge needs as they complete their recuperation at home. Indeed, Arora et al. $^{8}$ indicate that posthospitalization problems may be more the rule than the exception, and that specific types of problems can be foreseen. Most commonly reported were challenges obtaining follow-up appointments, difficulties managing or obtaining medications, feeling unprepared for discharge, having unanswered questions, or needing an urgent reevaluation. While well organized predischarge efforts help to prepare patients, even the most perfect discharge process cannot anticipate all possible pitfalls. Fortunately, most postdischarge problems can be effectively handled by those who often know the patient best, the patient's primary care team. The outpatient team is ideally situated to assist patients with the logistics of accessing the care system, to provide ongoing education, and to help with such basic needs as transportation and social support. It makes sense that such personalized outreach can prevent small problems from blossoming into more serious issues that might ultimately require rehospitalization.

Upon discharge, patients and families are also often expected to assume new self-care responsibilities, to implement new dietary restrictions, to use new medications, and to monitor and respond to new and evolving symptoms. Gaining the knowledge, the confidence, and the experience to adopt new behaviors is critical to successful postdischarge self-care. Adult learning theory informs us that edu- cation is an ongoing process. Mastering new material occurs with repetition, over time, and under different circumstances. An ancient Chinese proverb encapsulates the key aspects of learning:

- I hear and I forget;

- I see and I remember;

- I do and I understand.

Thus, a single didactic discharge session in the hospital is unlikely to provide patients with sufficient depth of understanding that one attains through experiential learning. Hospital-based discharge teaching is further compromised in the setting of patient fatigue, anxiety and illness: it is not surprising that patients comprehend and retain only $50 \%$ of the medical information discussed with their physicians. $^{15}$

While "teach back" has been effectively used to ensure that information is registered when initially presented, it does not ensure that information has been internalized in such a way that it can be utilized hours or days later. Instead, it is the active engagement with the primary care team that provides opportunities for ongoing learning, personalized to the educational needs of each patient. With nurses, dieticians, pharmacists, and medical educators playing a central guiding role, patients can receive appropriately tailored instruction, as well as opportunities to practically apply their new knowledge.

The evolving partnership among hospitals, hospitalists, and primary care holds great promise to reduce avoidable readmissions, and the Patient Protection and Affordable Care Act of 2010 will provide financial incentives to support this partnership. Health care reform aims to adjust hospital payments based on rates of preventable Medicare readmissions; bundling payments (paying for episodes of illness based on outcomes) and accountable care organizations (ACOs) will ideally foster seamless care coordination. ${ }^{16}$ Nurturing and developing this collaboration between the inpatient and outpatient care teams will be essential as we seek to provide patients the safest transition possible from the hospital to home.

\section{Address for correspondence and reprint requests:}

Richard B. Balaban, MD, 26 Central St. Somerville, MA 02143; Telephone: 617-591-6300; Fax: 617-591-6340; E-mail:

rbalaban@massmed.org Received 25 June 2010; accepted 25 June 2010 .

\section{References}

1. Jack BW, Chetty VK, Anthony D, et al. A reengineered hospital discharge program to decrease rehospitalization: a randomized trial. Ann Intern Med. 2009;150(3):178-187.

2. Coleman EA, Parry C, Chalmers S, Min SJ. The care transitions intervention: results of a randomized controlled trial. Arch Intern Med. 2006; 166(17):1822-1828.

3. Balaban RB, Weissman JS, Samuel PA, Woolhandler S. Redefining and redesigning hospital discharge to enhance patient care: a randomized controlled study. J Gen Intern Med. 2008;23(8):1228-1233. 
4. Koehler BE, Richter KM, Youngblood L, et al. Reduction of 30-day postdischarge hospital readmission or emergency department (ED) visit rates in high-risk elderly medical patients through delivery of a targeted care bundle. J Hosp Med. 2009;4(4):211-218.

5. Snow V, Beck D, Budnitz T, et al. Transitions of Care Consensus policy statement: American College of Physicians, Society of General Internal Medicine, Society of Hospital Medicine, American Geriatrics Society, American College Of Emergency Physicians, and Society for Academic Emergency Medicine. J Hosp Med. 2009;4(6):364-370.

6. van Walraven et al. Independent association of provider and information continuity on outcomes after hospital discharge: implications for hospitalists. J Hosp Med. 2010;5(7):398-405.

7. Misky et al. Post-hospitalization transitions: examining the effects of timing of primary care follow-up. J Hosp Med. 2010;5(7):392-397.

8. Arora et al. Problems after discharge and understanding of communication with their PCPs among hospitalized seniors: a mixed methods study. J Hosp Med. 2010;5(7):385-391.

9. Mitchell et al. Post-discharge hospital utilization among adult medical inpatients with depressive symptoms. J Hosp Med. 2010;5(7):378-384.
10. Kartha A, Anthony D, Manasseh CS, et al. Depression Is a risk factor for rehospitalization in medical inpatients. Prim Care Companion J Clin Psychiatry. 2007;9(4):256-262.

11. Jencks SF, Williams MV, Coleman EA. Rehospitalizations among patients in the Medicare fee-for-service program. N Engl J Med. 2 2009;360(14): 1418-1428.

12. Dorr DA, Wilcox AB, Brunker CP, Burdon RE, Donnelly SM. The effect of technology-supported, multidisease care management on the mortality and hospitalization of seniors. J Am Geriatr Soc. 2008;56(12): 2195-2202.

13. Leff B, Reider L, Frick KD, et al. Guided care and the cost of complex healthcare: a preliminary report. Am J Manag Care. 2009;15(8):555-559.

14. Counsell SR, Callahan CM, Clark DO, et al. Geriatric care management for low-income seniors: a randomized controlled trial. JAMA. 2007; 298(22):2623-2633.

15. Kessels RP. Patients' memory for medical information. J R Soc Med. 2003; 96(5):219-222.

16. Wachter RM. Understanding the new vocabulary of healthcare reform. J Hosp Med. 2010;5(4):197-199. 